The Open Respiratory Medicine
CrossMark
Journal
Content list available at: www.benthamopen.com/TORMJ/
DOI: $10.2174 / 1874306401711010047$

\title{
LETTER
}

\section{Bronchodilator Response Assessment of the Small Airways Obstructive Pattern}

Plamen Bokov ${ }^{1,2}$, Clémence Martin ${ }^{1}$, Sémia Graba ${ }^{1}$, Karine Gillet-Juvin ${ }^{1}$, Mohamed Essalhi ${ }^{1}$ and Christophe Delclaux ${ }^{1,2, *}$

${ }^{\prime}$ AP-HP ; Hôpital Européen Georges Pompidou ; Service de Physiologie, Paris. France

${ }^{2}$ Université Paris Descartes, Sorbonne Paris Cité, Faculté de Médecine, Paris. France

Received: April 26, 2017

Revised: May 25, 2017

Accepted: July 06, 2017

\section{Abstract:}

\section{Background:}

A concomitant decrease in $\mathrm{FEV}_{1}$ and $\mathrm{FVC}$ with normal $\mathrm{FEV}_{1} / \mathrm{FVC}$ ratio and TLC defines small airways obstructive pattern (SAOP) and constitutes a classic pitfall of pulmonary-function-tests interpretation.

\section{Objective:}

To evaluate the prevalence of flow- $\left(\mathrm{FEV}_{1}\right.$ increase $\geq 12 \%$ and $200 \mathrm{~mL}$ ), volume- (FVC or inspiratory capacity [IC] increase $\geq 12 \%$ and $200 \mathrm{~mL}$ ), flow and volume-, and non-response to bronchodilation in patients with SAOP. An additional objective was to assess whether impulse oscillometry (IOS) parameters allow the diagnosis of SAOP and its reversibility.

\section{Methods:}

Fifty consecutive adult patients with $\mathrm{SAOP}\left(\mathrm{FEV}_{1}\right.$ and $\mathrm{FVC}<$ lower limit of normal, $\mathrm{FEV}_{1} / \mathrm{FVC}$ and $\mathrm{TLC}>$ lower limit of normal) diagnosed on spirometry and plethysmography underwent the assessment of reversibility (400 $\mu \mathrm{g}$ salbutamol) on FEV $\mathrm{FVC}_{1}$, IC and IOS parameters.

Results:

The diseases most frequently associated with SAOP were COPD and asthma (26 and 15 patients, respectively). Six patients were flow-responders, 20 were volume-responders, 9 were flow and volume-responders and 15 patients were non-responders. Overall, 26 patients had a significant improvement of IC, and 35 / 50 (70\%, 95\% CI: 57-83) exhibited a significant bronchodilator response. The difference between $\operatorname{Rrs}_{5 \mathrm{~Hz}}$ and $\mathrm{Rrs}_{20 \mathrm{~Hz}}$ was increased in 28/50 patients (56\%, 95\%CI: $42-70$ with value higher than upper limit of normal) and its decrease after bronchodilator significantly correlated to $\mathrm{FEV}_{1}$ increase only, suggesting proximal airway assessment.

\section{Conclusion:}

A significant reversibility, mainly assessed on IC increase, is frequent in Small Airways Obstructive Pattern. Impulse oscillometry is of limited value in this context because of its low sensitivity.

Keywords: Pulmonary function testing, Bronchodilator response, Impulse oscillometry, Obstructive defect, Inspiratory capacity, Distal airways.

\footnotetext{
* Address correspondence to this author at the Service de Physiologie Pédiatrique, Université Paris Diderot, Hôpital Robert Debré, 48, boulevard Sérurier, 75019 Paris, France; Tel: 33140034190; E-mail: christophe.delclaux@aphp.fr
} 


\section{INTRODUCTION}

Pellegrino et al. in the interpretative strategies for lung function tests stated that special attention must be paid when $\mathrm{FEV}_{1}$ and $\mathrm{FVC}$ are concomitantly decreased and the $\mathrm{FEV}_{1} / \mathrm{FVC}$ ratio is normal or almost normal. Apart incomplete inhalation or exhalation, these authors stated that a "possible cause of this pattern is patchy collapse of small airways early in exhalation" [1]. This small airways obstructive pattern (SAOP) is not infrequent, represents $\sim 7 \%$ to $10 \%$ of all pulmonary function tests in two large databases and is not specific of any disease in adults [2, 3]. It can also be encountered in asthmatic children [4]. Since this pattern is deemed to be the consequence of "patchy collapse of small airways early in exhalation" one may wonder whether bronchodilator response should be assessed on flow (increase in $\mathrm{FEV}_{1}$ ), volume (FVC and/or inspiratory capacity [IC] [5]) or both flow and volume. Moreover, improvements in IC correlate with improvements in exercise tolerance and endurance, which are recognized as important goals of disease management. Consequently, the primary objective of our study was to assess whether bronchodilator response should be assessed conventionally using $\mathrm{FEV}_{1}$ and $\mathrm{FVC}$, or using IC.

SAOP has initially been defined as a pseudo-restrictive syndrome because of the reduction of $\mathrm{FEV}_{1}$ and $\mathrm{FVC}$ with normal $\mathrm{FEV}_{1} / \mathrm{FVC}$ ratio. If TLC measurement is made using dilution techniques, one may wrongly conclude that the defect is restrictive [3]. Since body plethysmography is not available in all pulmonary function testing laboratories, another method for SAOP detection is mandatory. Impulse oscillometry (IOS) has the advantage of being simple to use and is effort-independent [6]. The contribution of the distal airways could be determined by the fall in resistance from 5 $\mathrm{Hz}$ to $20 \mathrm{~Hz}\left(\Delta \mathrm{Rrs}_{5 \mathrm{~Hz}-20 \mathrm{~Hz}}\right)[6]$ and could therefore be useful to detect SAOP. Our additional objective was to assess the usefulness of IOS to diagnose SAOP (sensitivity) and its reversibility.

\section{MATERIAL AND METHODS}

\subsection{Patients}

We enrolled prospectively 50 consecutive Caucasian patients exhibiting SAOP defined by a decrease in both FEV 1 and FVC (< lower limit of normal [LLN]) and normal (above LLN) $\mathrm{FEV}_{1} / \mathrm{FVC}$ ratio and TLC (the latter being measured by body plethysmography), while receiving no bronchodilator treatment. Lung transplantation was a non inclusion criterion.

The study was approved by the Institutional Review Board of the French learned society for respiratory medicine SPLF- (CEPRO-2016-014) and all patients gave informed consent.

\subsection{Pulmonary Function Tests}

Complete lung function testing was obtained with the MasterScreen ${ }^{\text {TM }}$ PFT system (Master Scope Body, MS-IOS, Jaeger, Carefusion Technologies, Yorba Linda, California, USA), according to international recommendations [7, 8].

IOS parameters: Pressure oscillation with frequencies varying between 5 and $35 \mathrm{~Hz}$ were superimposed on tidal breathing, producing recordable waveforms. Advanced signal processing of the impedance of the respiratory system (Zrs) was then used to extract the respiratory mechanic components from the recorded waveforms. The primary outcomes resistance of the respiratory system (Rrs) and reactance (Xrs) were plotted against frequency. Resistance is defined as the ratio of the pressure drop $(\mathrm{kPa})$ over an airway segment and the flow $\left(\mathrm{L} \cdot \mathrm{s}^{-1}\right)$ through that segment. Reactance is simplistically described as the amount of recoil generated against the pressure wave. We used the following IOS variables: impedance, resistance and reactance at $5 \mathrm{~Hz}$; the fall in resistance between R5 and R20 $\left(\Delta \operatorname{Rrs}_{5 \mathrm{~Hz}-2 \mathrm{~Hz}}\right)$, reflecting "peripheral" airway resistance; and the square root of the integrated area of low frequency reactance $(\mathrm{AX})$, assumed to reflect the reactance of the "peripheral" airways, and serving as a confirmatory index to $\Delta \operatorname{Rrs}_{5 \mathrm{~Hz}-20 \mathrm{~Hz}}$.

At baseline were performed IOS, spirometry, slow vital capacity and static volumes measurements. Bronchodilator response to $400 \mu \mathrm{g}$ salbutamol was evaluated using spirometry, slow vital capacity (IC recording) and IOS

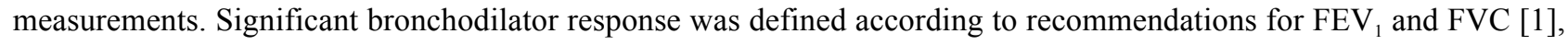
and by an increase in IC of at least $12 \%$ from baseline and $\geq 200 \mathrm{~mL}$ as proposed by Celli and colleagues [9]. Predicted values of spirometry, static lung volumes and IOS parameters were those of Global Lungs Initiative, European Community for Steel and Coal and of the KORA Study Group, respectively [10 - 12]. 


\subsection{Statistical Analyses}

Results are expressed as median $\left[25^{\text {th }}-75^{\text {th }}\right.$ percentiles $]$. Univariate correlations were estimated using non parametric Spearman coefficients. A P value $<0.05$ was deemed significant. All statistical analyses were performed with Statview 5.0 software (SAS institute, Cary, North Carolina, USA).

Sample size calculation: due to its descriptive design our objective was to give observed percentages with a $95 \% \mathrm{CI}$ range $<30 \%$ that can be obtained with a sample of 50 patients.

\section{RESULTS}

Patients' description and lung function tests results are listed in Table 1.

Table 1. Clinical and functional characteristics of the patients.

\begin{tabular}{|c|c|}
\hline n or median $\left[25^{\text {th }}-75^{\text {th }}\right.$ percentile $]$ & \\
\hline $\mathrm{N}$ patients & 50 \\
\hline Sex ratio, $\mathrm{F} / \mathrm{M}$ & $27 / 23$ \\
\hline Age, years & $67[50 ; 72]$ \\
\hline BMI & $26.9[23.9 ; 32.4]$ \\
\hline Underlying disease & - \\
\hline asthma & 15 \\
\hline COPD & 26 \\
\hline bronchiectasis & 6 \\
\hline sarcoidosis & 2 \\
\hline interstitial disease & 1 \\
\hline Tobacco history & - \\
\hline current-smoker, $\mathrm{n}$ & 9 \\
\hline ex-smoker, $\mathrm{n}$ & 20 \\
\hline never-smoker, $\mathrm{n}$ & 21 \\
\hline pack-years & $33[19 ; 50]$ \\
\hline MRC score & $2.0[1.0 ; 3.0]$ \\
\hline Lung function & - \\
\hline $\mathrm{FEV}_{1}, \mathrm{~L}$ & $1.72[1.27 ; 2.12]$ \\
\hline $\mathrm{FEV}_{1}, \%$ predicted & $59[53 ; 65]$ \\
\hline $\mathrm{FEV}_{1}, \mathrm{Z}$-score & $-2.53[-2.96 ;-2.12]$ \\
\hline FVC, $\mathrm{L}$ & $2.22[1.64 ; 2.79]$ \\
\hline FVC, $\%$ predicted & $63[54 ; 67]$ \\
\hline FVC, Z-score & $-2.55[-2.88 ;-2.20]$ \\
\hline Slow inspiratory VC, L & $2.22[1.61 ; 2.80]$ \\
\hline $\mathrm{FEV}_{1} / \mathrm{FVC}$ & $0.74[0.70 ; 0.78]$ \\
\hline $\mathrm{FEV}_{1} / \mathrm{FVC}, \%$ predicted & $94[90 ; 98]$ \\
\hline $\mathrm{FEV}_{1} / \mathrm{FVC}, \mathrm{Z}$-score & $-0.68[-0.98 ;-0.18]$ \\
\hline $\mathrm{IC}, \mathrm{L}$ & $1.62[1.20 ; 2.20]$ \\
\hline TLC, $\mathrm{L}$ & $4.93[4.16 ; 6.37]$ \\
\hline TLC, $\%$ predicted & $90[85 ; 95]$ \\
\hline FRC, $\mathrm{L}$ & $3.31[2.89 ; 4.28]$ \\
\hline FRC, $\%$ predicted & $110[99 ; 131]$ \\
\hline $\mathrm{RV}, \mathrm{L}$ & $2.80[2.13 ; 3.40]$ \\
\hline $\mathrm{RV}, \%$ predicted & $132[117 ; 154]$ \\
\hline RV/TLC & $0.55[0.49 ; 0.64]$ \\
\hline RV/TLC, $\%$ predicted & $142[132 ; 152]$ \\
\hline sRaw, kPa.s & $1.63[1.15 ; 2.26]$ \\
\hline Raw, kPa.s/L & $0.41[0.30 ; 0.52]$ \\
\hline Impulse Oscillometry & - \\
\hline $\mathrm{Zrs}_{\mathrm{SHz}}, \mathrm{kPa} . \mathrm{s} / \mathrm{L}$ & $0.48[0.40 ; 0.63]$ \\
\hline $\mathrm{Zrs}_{\mathrm{SHz}}, \%$ predicted & $147[128 ; 175]$ \\
\hline
\end{tabular}


(Table 1) contd.....

\begin{tabular}{|c|c|}
\hline n or median $\left[25^{\text {th }}-75^{\text {th }}\right.$ percentile $]$ & \\
\hline $\operatorname{Rrs}_{5 \mathrm{~Hz}}, \mathrm{kPa} . \mathrm{s} / \mathrm{L}$ & $0.42[0.34 ; 0.51]$ \\
\hline $\operatorname{Rrs}_{5 \mathrm{~Hz}}, \%$ predicted & $134[121 ; 167]$ \\
\hline $\mathrm{Xrs}_{5 \mathrm{~Hz}}, \mathrm{kPa} . \mathrm{s} / \mathrm{L}$ & $-0.16[-0.23 ;-0.11]$ \\
\hline $\mathrm{Xrs}_{5 \mathrm{~Hz}}, \%$ predicted & $166[106 ; 190]$ \\
\hline$\Delta \mathrm{Rrs}_{5 \mathrm{~Hz}-2 \mathrm{~Hz}}, \mathrm{kPa} . \mathrm{s} / \mathrm{L}$ & $0.15[0.10 ; 0.21]$ \\
\hline$\Delta \mathrm{Rrs}_{5 \mathrm{~Hz}-2 \mathrm{~Hz}}, \%$ predicted & $213[165 ; 296]$ \\
\hline AX, Hz.kPa.s/L & $1.41[0.91 ; 1.97]$ \\
\hline AX, \% predicted & $363[268 ; 514]$ \\
\hline Bronchodilator response & - \\
\hline $\mathrm{FEV}_{1}, \%$ increase & $+8[+1 ;+12]$ \\
\hline $\mathrm{FVC}, \%$ increase & $+6[+1 ;+12]$ \\
\hline IC, $\%$ increase & $+12[+3 ;+22]$ \\
\hline $\mathrm{Zrs}_{5 \mathrm{~Hz}}, \%$ decrease & $0[-9 ;+12]$ \\
\hline $\operatorname{Rrs}_{5 \mathrm{~Hz}}, \%$ decrease & $+12[-3 ;+21]$ \\
\hline $\mathrm{Xrs}_{5 \mathrm{~Hz}}$, (post-pre) & $0.03[0.01 ; 0.07]$ \\
\hline$\Delta \operatorname{Rrs}_{5 \mathrm{~Hz}-20 \mathrm{~Hz}}, \%$ decrease & $+25[+10 ;+33]$ \\
\hline $\mathrm{AX}, \%$ decrease & $+32[+17 ;+47]$ \\
\hline
\end{tabular}

Based on $\mathrm{FEV}_{1} \%$ predicted, a moderate to moderately severe defect was observed, associated with mild hyperinflation (increase in RV).

IOS measurements $\left(\operatorname{Rrs}_{5 \mathrm{~Hz}}\right)$ were coherent with plethysmographic measurements of airway resistance (Raw), $\operatorname{Rrs}_{5 \mathrm{~Hz}}$ being slightly higher. $\Delta \operatorname{Rrs}_{5 \mathrm{~Hz}-20 \mathrm{~Hz}}$ was increased in $28 / 50$ patients $(56 \%, 95 \% \mathrm{CI}: 42-70$, with a higher value than upper limit of normal) that suggested airway obstruction (SAOP diagnosis) before TLC measurement, while AX was elevated (above upper limit of normal) in $42 / 50$ patients.

$\mathrm{RV} / \mathrm{TLC} \%$ predicted only correlated with $\mathrm{FEV}_{1 \%}$ predicted $(\mathrm{rho}=-0.528, \mathrm{p}=0.0002)$ and $\mathrm{FVC} \%$ predicted (rho $=$ $-0.531, \mathrm{p}=0.0002)$, no significant correlation was evidenced with IOS parameters.

Fifteen patients (30\%, 95\%CI: 17-43) exhibited a significant $\mathrm{FEV}_{1}$ reversibility Fig. (1). Twenty-six patients (52\%, 95\%CI: 38-66) exhibited a significant IC reversibility Fig. (1), while 13 patients (26\%, 95\%CI: $14-38)$ exhibited a significant FVC reversibility.

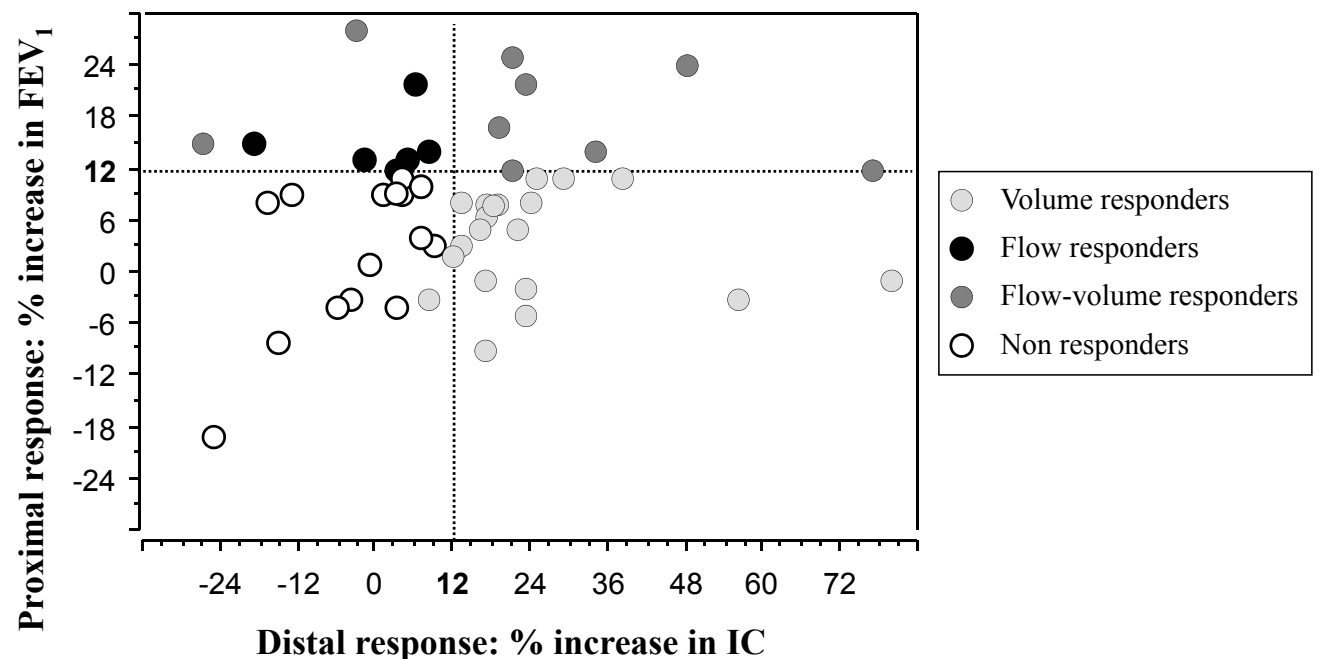

Fig. (1). Relationship between proximal (increase in $\mathrm{FEV}_{1}$ ) and distal (increase in IC) response to bronchodilator. Dotted lines are $12 \%$ increase in $\mathrm{FEV}_{1}$ or IC as compared to baseline value. There was a non significant relationship between the two responses $(\mathrm{p}=0.465)$. Three patients, two with flow-responder group and one with non responder group, depicted a significant FVC response without significant IC response. 
Six patients were flow-responders (proximal response), 20 were volume-responders (increase in IC and/or FVC: distal response), 9 were flow and volume responders (overall response) and 15 patients were non responders. Overall, 35 / 50 (70\%, 95\%CI: 57-83) exhibited a significant bronchodilator response Fig. (1).

Table 2 describes the correlations between the different parameters assessing bronchodilator response. IOS parameters correlated to $\mathrm{FEV}_{1}$ response only, further suggesting their proximal assessment.

Table 2. Correlations between the bronchodilator response parameters.

\begin{tabular}{|c|c|c|c|c|c|c|c|}
\hline Rho Values & $\begin{array}{l}\mathrm{FEV}_{1}, \% \\
\text { Increase }\end{array}$ & $\begin{array}{l}\text { FVC, \% } \\
\text { Increase }\end{array}$ & IC, \% Increase & $\begin{array}{l}\mathrm{Zrs}_{5 \mathrm{~Hz}}, \% \\
\text { Decrease }\end{array}$ & $\begin{array}{l}\operatorname{Rrs}_{5 \mathrm{~Hz}}, \% \\
\text { Decrease }\end{array}$ & $\begin{array}{c}\Delta \mathrm{Rrs}_{5 \mathrm{~Hz}-20 \mathrm{~Hz}}, \% \\
\text { Decrease }\end{array}$ & $\begin{array}{c}\text { AX, \% } \\
\text { Decrease }\end{array}$ \\
\hline \multicolumn{8}{|l|}{$\mathrm{FEV}_{1}, \%$ increase } \\
\hline FVC, \% increase & 0.301 & & & & & & \\
\hline IC, \% increase & 0.084 & 0.289 & & & & & \\
\hline $\mathrm{Zrs}_{5 \mathrm{~Hz}}, \%$ decrease & 0.272 & 0.197 & 0.074 & & & & \\
\hline $\operatorname{Rrs}_{5 \mathrm{~Hz}}, \%$ decrease & 0.269 & 0.164 & 0.025 & 0.912 & & & \\
\hline$\Delta \mathrm{Rrs}_{5 \mathrm{~Hz}-2 \mathrm{~Hz}}, \%$ decrease & 0.289 & 0.161 & 0.013 & 0.836 & 0.876 & & \\
\hline $\mathrm{AX}, \%$ decrease & 0.295 & 0.190 & -0.032 & 0.816 & 0.769 & 0.813 & \\
\hline $\mathrm{Xrs}_{5 \mathrm{~Hz}}$, (post-pre) & 0.100 & -0.001 & 0.039 & 0.243 & 0.302 & 0.290 & 0.526 \\
\hline
\end{tabular}

Rho values are given for the correlations. Bold values denotes significant $(\mathrm{p}<0.05)$ correlations using Spearman test.

\section{DISCUSSION}

Our descriptive prospective study demonstrates that the bronchodilator response of peripheral airways related to SAOP should be evaluated using the increase in IC rather than the conventional increase in FEV $\mathrm{V}_{1}$ that assesses more central airways or even the increase in FVC. The study also shows that impedance measurements using the IOS method was not sufficiently sensitive to detect SAOP.

The first issue is whether the abnormal pattern of SAOP is always obstructive. From a physiological point of view (one compartment model for instance) [13] there are only three mechanisms explaining a decrease in $\mathrm{FEV}_{1}$, obstructive, restrictive and mixed defects. Since the pattern is not restrictive (normal TLC), the defect is obstructive. The associated hyperinflation (increase in RV and sometimes FRC) further suggests peripheral obstruction. Logically, the ATS/ERS consensus on clinical pulmonary function testing stated that this pattern would be related to patchy collapse of small airways early in exhalation after exclusion of technical problems. The discussion comes from the clinical conditions associated with SAOP such as restricted thoracic expansion (obesity, thoracic deformation without restrictive defect), justifying the label of "non-specific pattern" for some investigators [2, 14], which is indefensible from a physiological basis. Nevertheless, the SAOP is a syndrome related to non-specific conditions leading to peripheral obstruction. The present study shows that a significant proximal and/or distal reversibility was found in $70 \%$ of the patients that clearly demonstrates the obstructive nature of the defect.

The causes of SAOP were those previously described, COPD and asthma being the more prevalent [3]. The prevalence of $30 \% \mathrm{FEV}_{1}$ reversibility is higher than that observed by Iyer et al. (13\%, 95\%CI: 11.2 to 14.8) [14], which

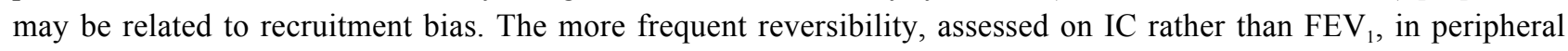
airway diseases (volume response) has previously been reported in COPD [15].

One may wonder why a more prevalent IC response than FVC response was evidenced. Our hypothesis is that patients exhibiting SAOP are characterized by a specific tendency to collapse their small airways in exhalation (often remaining after bronchodilator assessment), even from FRC to RV explaining that slow inspiratory vital capacity is similarly reduced than expiratory FVC. Consequently, significant bronchodilation is more often obtained on FRC (and IC) than on RV (and FVC). Moreover, the measurement of FVC is obtained after deep inspiration that may reduce FVC due to its bronchoconstrictor effect [16]. Along this line, the recent study of Jarenback and colleagues, in COPD and control patients, showed that a significant correlation between $\Delta \mathrm{FVC} \%$ predicted and $\Delta \mathrm{RV} \%$ predicted after bronchodilation was only evidenced in the subgroup of patients with $\mathrm{FEV}_{1}<65 \%$ predicted [17]. This result highlights that a reduction of hyperinflation is probably not necessarily associated with an increase in FVC.

Whether IOS parameters can assess peripheral airways obstruction remains debated because this statement mainly relies on modelling approaches $[6,18]$. Based on simplistic physical grounds from healthy lungs, airway resistance measurement is deemed to assess proximal airways [1]. From previous studies, we suggested that 1) peripheral airways can significantly contribute to airway resistance in COPD patients based on a modelling approach [19], 2) airway 
resistance and specific airway resistance are often increased ( 50\%) in SAOP [3] and 3) some respiratory system resistance parameters could assess peripheral airways in COPD patients based on a statistical approach [20].

Despite this background, several arguments suggest that IOS parameters were not sensitive to detect small airways disease. Firstly, the IOS parameter $\Delta \mathrm{Rrs}_{5 \mathrm{~Hz}-20 \mathrm{~Hz}}$, deemed to assess peripheral obstruction, was inconsistently increased $(56 \%)$ and its change after bronchodilator was associated with $\mathrm{FEV}_{1}$ change only. AX was more frequently elevated, but its increase does not necessarily traduce an obstructive defect, as demonstrated in interstitial lung diseases [21]. Since IOS does not rely on forced manoeuvres, it may reduce the effects of premature airway closure seen during forced spirometry manoeuvres, which could impede its ability to detect SAOP. Secondly, a significant increase in IC reflecting the decrease in dynamic hyperinflation, related to peripheral airways dilation, was not associated with any significant improvement in IOS parameters.

In conclusion, a significant reversibility is frequent (70\%) in patients depicting a Small Airways Obstructive Pattern, mainly assessed by inspiratory capacity increase. Impulse oscillometry is of limited value in this context since only half of the patients were detected as obstructive using this method.

\section{LIST OF ABBREVIATIONS}

$\begin{array}{lll}\mathbf{S A O P} & = & \begin{array}{l}\text { Small Airways Obstructive Pattern } \\ \mathbf{I O S}\end{array} \\ \begin{array}{l}\Delta \mathbf{R r s}_{\mathbf{5 H z}-\mathbf{2 0 H z}} \\ \mathbf{L L N}\end{array} & = & \text { Impulse Oscillometry } \\ \mathbf{Z r s} & = & \text { Resistance from } 5 \mathrm{~Hz} \text { to } 20 \mathrm{~Hz} \\ \mathbf{R r s} & = & \text { Impedance of the Respiratory System } \\ \mathbf{X r s} & = & \text { Reactance of the Respiratory System } \\ \mathbf{A X} & = & \text { Square Root of the Integrated Area of low Frequency Reactance } \\ \mathbf{I C} & = & \text { Inspiratory Capacity }\end{array}$

\section{CONFLICT OF INTEREST}

The authors declare no conflict of interest, financial or otherwise.

\section{ACKNOWLEDGEMENTS}

The authors wish to thank the technicians of the respiratory function unit for their expert assistance (Françoise Génisty; Sandrine Desbrosses; Marien Bokouabassa; Farid Sekaii)

\section{REFERENCES}

[1] Pellegrino R, Viegi G, Brusasco V, et al. Interpretative strategies for lung function tests. Eur Respir J 2005; $26(5)$ : $948-68$. [http://dx.doi.org/10.1183/09031936.05.00035205] [PMID: 16264058]

[2] Hyatt RE, Cowl CT, Bjoraker JA, Scanlon PD. Conditions associated with an abnormal nonspecific pattern of pulmonary function tests. Chest 2009; 135(2): 419-24. [http://dx.doi.org/10.1378/chest.08-1235] [PMID: 18812444]

[3] Chevalier-Bidaud B, Gillet-Juvin K, Callens E, et al. Non specific pattern of lung function in a respiratory physiology unit: causes and prevalence: Results of an observational cross-sectional and longitudinal study. BMC Pulm Med 2014; $14: 148$. [http://dx.doi.org/10.1186/1471-2466-14-148] [PMID: 25233902]

[4] Mahut B, Bokov P, Delclaux C. Abnormalities of plethysmographic lung volumes in asthmatic children. Respir Med 2010; 104(7): 966-71. [http://dx.doi.org/10.1016/j.rmed.2010.01.015] [PMID: 20149963]

[5] Tantucci C, Duguet A, Similowski T, Zelter M, Derenne JP, Milic-Emili J. Effect of salbutamol on dynamic hyperinflation in chronic obstructive pulmonary disease patients. Eur Respir J 1998; 12(4): 799-804. [http://dx.doi.org/10.1183/09031936.98.12040799] [PMID: 9817148]

[6] Oostveen E, MacLeod D, Lorino H, et al. The forced oscillation technique in clinical practice: methodology, recommendations and future developments. Eur Respir J 2003; 22(6): 1026-41. [http://dx.doi.org/10.1183/09031936.03.00089403] [PMID: 14680096]

[7] Miller MR, Hankinson J, Brusasco V, et al. Standardisation of spirometry. Eur Respir J 2005; 26(2): $319-38$. [http://dx.doi.org/10.1183/09031936.05.00034805] [PMID: 16055882]

[8] Wanger J, Clausen JL, Coates A, et al. Standardisation of the measurement of lung volumes. Eur Respir J 2005; 26(3): 511-22. 
[http://dx.doi.org/10.1183/09031936.05.00035005] [PMID: 16135736]

[9] Celli BR, Tashkin DP, Rennard SI, McElhattan J, Martin UJ. Bronchodilator responsiveness and onset of effect with budesonide/formoterol pMDI in COPD. Respir Med 2011; 105(8): 1176-88.

[http://dx.doi.org/10.1016/j.rmed.2011.02.020] [PMID: 21531124]

[10] Quanjer PH, Stanojevic S, Cole TJ, et al. Multi-ethnic reference values for spirometry for the 3-95-yr age range: the global lung function 2012 equations. Eur Respir J 2012; 40(6): 1324-43. [http://dx.doi.org/10.1183/09031936.00080312] [PMID: 22743675]

[11] Quanjer PH, Tammeling GJ, Cotes JE, Pedersen OF, Peslin R, Yernault JC. Lung volumes and forced ventilatory flows. Report working party standardization of lung function tests, european community for steel and coal. Eur Respir J Suppl 1993; 16: 5-40. [http://dx.doi.org/10.1183/09041950.005s1693] [PMID: 8499054]

[12] Schulz H, Flexeder C, Behr J, et al. Reference values of impulse oscillometric lung function indices in adults of advanced age. PLoS One 2013; 8(5): e63366.

[http://dx.doi.org/10.1371/journal.pone.0063366] [PMID: 23691036]

[13] Mahut B, Trinquart L, Bokov P, et al. Relationships between specific airway resistance and forced expiratory flows in asthmatic children. PLoS One 2009; 4(4): e5270. [http://dx.doi.org/10.1371/journal.pone.0005270] [PMID: 19381269]

[14] Iyer VN, Schroeder DR, Parker KO, Hyatt RE, Scanlon PD. The nonspecific pulmonary function test: longitudinal follow-up and outcomes. Chest 2011; 139(4): 878-86. [http://dx.doi.org/10.1378/chest.10-0804] [PMID: 20724741]

[15] Pellegrino R, Rodarte JR, Brusasco V. Assessing the reversibility of airway obstruction. Chest 1998; 114(6): 1607-12. [http://dx.doi.org/10.1378/chest.114.6.1607] [PMID: 9872196]

[16] Delclaux C, Zerah-Lancner F, Mahut B, et al. Alveolar nitric oxide and effect of deep inspiration during methacholine challenge. Chest 2005; 127(5): $1696-702$.

[http://dx.doi.org/10.1378/chest.127.5.1696] [PMID: 15888848]

[17] Jarenbäck L, Eriksson G, Peterson S, Ankerst J, Bjermer L, Tufvesson E. Bronchodilator response of advanced lung function parameters depending on COPD severity. Int J Chron Obstruct Pulmon Dis 2016; 11: 2939-50. [http://dx.doi.org/10.2147/COPD.S111573] [PMID: 27932874]

[18] Goldman MD, Saadeh C, Ross D. Clinical applications of forced oscillation to assess peripheral airway function. Respir Physiol Neurobiol 2005; 148(1-2): 179-94. [http://dx.doi.org/10.1016/j.resp.2005.05.026] [PMID: 15990365]

[19] Bokov P, Mauroy B, Mahut B, Delclaux C, Flaud P. Homothety ratio of airway diameters and site of airway resistance in healthy and COPD subjects. Respir Physiol Neurobiol 2014; 191: 38-43.

[http://dx.doi.org/10.1016/j.resp.2013.10.015] [PMID: 24200643]

[20] Mahut B, Caumont-Prim A, Plantier L, et al. Relationships between respiratory and airway resistances and activity-related dyspnea in patients with chronic obstructive pulmonary disease. Int J Chron Obstruct Pulmon Dis 2012; 7: 165-71. [PMID: 22500118]

[21] Sugiyama A, Hattori N, Haruta Y, et al. Characteristics of inspiratory and expiratory reactance in interstitial lung disease. Respir Med 2013; 107(6): 875-82.

[http://dx.doi.org/10.1016/j.rmed.2013.03.005] [PMID: 23582576]

\section{(C) 2017 Bokov et al.}

This is an open access article distributed under the terms of the Creative Commons Attribution 4.0 International Public License (CC-BY 4.0), a copy of which is available at: https://creativecommons.org/licenses/by/4.0/legalcode. This license permits unrestricted use, distribution, and reproduction in any medium, provided the original author and source are credited. 